\title{
High dose of histone deacetylase inhibitors affects insulin secretory mechanism of pancreatic beta cell line
}

\author{
Eiji Үамато \\ ${ }^{1}$ Department of Nutrition and Food Sciences, Mukogawa Women's University, Nishinomiya, Hyogo, Japan \\ E-mail: yamato@mukogawa-u.ac.jp
}

Objective. Histone deacytylase inhibitors (HDACis) inhibit the deacetylation of the lysine residue of proteins, including histones, and regulate the transcription of a variety of genes. Recently, HDACis have been used clinically as anti-cancer drugs and possible anti-diabetic drugs. Even though HDACis have been proven to protect the cytokine-induced damage of pancreatic beta cells, evidence also shows that high doses of HDACis are cytotoxic. In the present study, we, therefore, investigated the effect of HDACis on insulin secretion in a pancreatic beta cell line.

Methods. Pancreatic beta cells MIN6 were treated with selected HDACis (trichostatin A, TSA; valproic acid, VPA; and sodium butyrate, $\mathrm{NaB}$ ) in medium supplemented with $25 \mathrm{mM}$ glucose and $13 \%$ heat-inactivated fetal bovine serum (FBS) for indicated time intervals. Protein expression of Pdx1 and Mafa in MIN6 cells was demonstrated by immunohistochemistry and immunocytochemistry, expression of Pdx1 and Mafa genes was measured by quantitative RT-PCR method. Insulin release from MIN6 cells and insulin cell content were estimated by ELISA kit. Superoxide production in MIN6 cells was measured using a Total ROS/Superoxide Detection System.

Results. TSA, VPA, and NaB inhibited the expression of Pdx1 and Mafa genes and their products. TSA treatment led to beta cell malfunction, characterized by enhanced insulin secretion at 3 and $9 \mathrm{mM}$ glucose, but impaired insulin secretion at 15 and $25 \mathrm{mM}$ glucose. Thus, TSA induced dysregulation of the insulin secretion mechanism. TSA also enhanced reactive oxygen species production in pancreatic beta cells.

Conclusions. Our results showed that HDACis caused failure to suppress insulin secretion at low glucose concentrations and enhance insulin secretion at high glucose concentrations. In other words, when these HDACis are used clinically, high doses of HDACis may cause hypoglycemia in the fasting state and hyperglycemia in the fed state. When using HDACis, physicians should, therefore, be aware of the capacity of these drugs to modulate the insulin secretory capacity of pancreatic beta cells.

Key words: trichostatin A, histone deacytylase inhibitor, beta cell line, insulin

Histone deacetylase inhibitors (HDACis) are small epigenetically active molecules (Marks 2010). They induce acetylation of the lysine residues of histones, as well as non-histone proteins, following altered genes' expression in response to physiological changes in cells (Halsall et al. 2012).
Recently, HDACis have been used clinically as anticancer drugs (Manal et al. 2016; Newbold 2016). It has been reported that HDACis revert cytokine-induced beta cell toxicity (Larsen et al. 2007; Susick et al. 2008; Lundh et al. 2012), improve insulin resistance (Christensen et al. 2011; Lundh et al. 2015), enhance insulin

Corresponding author: Eiji Yamato, M.D., Ph.D., Department of Nutrition and Food Sciences, Mukogawa Women's University, 6-46 Ikebiraki-cho, Nishinomiya, Hyogo 663-8558, Japan; phone and fax: +81-798-45-9926; e-mail: yamato@mukogawa-u.ac.jp. 
secretion (Tiernan et al. 2015), and stimulate pancreatic beta cell proliferation (Khan and Jena 2014; Plaisance et al. 2014). Therefore, HDACis are considered to be possible anti-diabetic drugs (Christensen et al. 2011; Khan and Jena 2015; Sharma and Taliyan 2016).

In contrast, recent reports have revealed that hydroxamic acid, a group of HDACis, inhibited gene expression of beta cell markers, including Pdxl, a key transcription factor (Kubicek et al. 2012). Therefore, the contribution of HDACis to the amelioration of pancreatic beta cell function must be elucidated. We investigated the effect of the hydroxamic acid, TSA, as well as other class of HDACis, including short-chain fatty acids, valproic acid (VPA), and sodium butyrate $(\mathrm{NaB})$ on pancreatic beta cell line, MIN6 cells.

\section{Materials and Methods}

Culture of MIN6 cells. MIN6 cells, clone 4,were maintained in Dulbecco's modified Eagle's medium containing $25 \mathrm{mM}$ glucose and $13 \%$ heat-inactivated FBS in a humidified $5 \% \mathrm{CO}_{2} / 95 \% \mathrm{O}_{2}$ incubator at $37^{\circ} \mathrm{C}$ (Miyazaki et al. 1990; Yamato et al. 2013). Incubation with HDACis was performed using $1 \mu \mathrm{M} \mathrm{TSA}, 10 \mathrm{mM}$ $\mathrm{VPA}$, and $10 \mathrm{mM} \mathrm{NaB}$ for $24 \mathrm{~h}$ unless stated otherwise.

Analysis of insulin release from MIN6 cells and insulin content. MIN6 cells were cultured with or without $1 \mu \mathrm{M}$ TSA for $24 \mathrm{~h}$. After washing, MIN6 cells were preincubated with $3.3 \mathrm{mM}$ glucose for $60 \mathrm{~min}$, followed by culture with insulin secretagogues $(3,9,15,25 \mathrm{mM}$ glucose, and $30 \mathrm{mM} \mathrm{KCl})$ in HEPES-buffered Krebs-Ringer solution for $60 \mathrm{~min}$. The supernatant was collected and assayed for insulin concentration using an enzyme-linked immunosorbent assay (ELISA) kit (Mercodia, Uppsala, Sweden). MIN6 cells were lysed with RIPA buffer and the protein concentration of the cell lysate was measured using the Bradford method (Biorad, Hercules, CA). To measure insulin content, MIN6 cells were lysed with acid ethanol and extracted overnight at $4{ }^{\circ} \mathrm{C}$, and the insulin concentration was measured by ELISA.

Immunocytochemistry. MIN6 cells were washed with phosphate-buffered saline (PBS) and fixed in $4 \%$ paraformaldehyde for $10 \mathrm{~min}$. After fixation, the cells were rinsed with PBS, incubated for $5 \mathrm{~min}$ in $1 \%$ Triton X-100, and, after a second wash, incubated in blocking reagent (Blocking One, Nakalai Tesk, Kyoto, Japan). For both immunohistochemistry and immunocytochemistry, samples were incubated with a primary antibody for $60 \mathrm{~min}$ at room temperature (RT), washed with PBS, then incubated with a secondary antibody for $60 \mathrm{~min}$ at RT. The primary antibodies were anti-pdx1 (Transgenic, Kumamoto, Japan), diluted 1:100, and anti-mafa (Bethyl, Montgomery, TX), diluted 1:100. The secondary antibody was Alexa Fluor 488-conjugated anti-rabbit IgG (Molecular Probes, OR), diluted 1:500.

Quantitative RT-PCR. Total RNA was extracted from MIN6 cells using the acid guanidinium-phenol-chloroform method and cDNA was synthesized using ReverTra Ace (Toyobo, Tokyo, Japan). Quantitative RT-PCR analysis was carried out using SYBR Premix Ex Taq (Takara, Otsu, Japan). The reaction was performed with $1 \mu \mathrm{l}$ cDNA per $25 \mu \mathrm{l}$ reaction using a 7300 Real-Time PCR System (Applied Biosystems, Foster City, CA) under the following thermal cycling conditions: $95^{\circ} \mathrm{C}$ for $10 \mathrm{~s}$ with no repeats, $95^{\circ} \mathrm{C}$ for $5 \mathrm{~s}$, and $60^{\circ} \mathrm{C}$ for $31 \mathrm{~s}$ with 40 repeats. The relative quantity of the target transcripts was estimated by the standard curve method and the values were standardized using the relative expression values of Rpl32. Primer sequences are available upon request.

Detection of reactive oxygen species (ROS). Superoxide production was measured using a Total ROS/Superoxide Detection System (Enzo, Farmingdale, NY, USA) according to the manufacturer's instruction. For oxidative stress, MIN6 cells were preincubated with $1 \mu \mathrm{M}$ TSA or control for $24 \mathrm{~h}$, then incubated with $40 \mathrm{mM}$ hydrogen peroxide $\left(\mathrm{H}_{2} \mathrm{O}_{2}\right)$ for $30 \mathrm{~min}$. Superoxide content was measured as the relative intensity of the cells using NIH Image software.

Statistical analysis. Results are presented as the mean \pm SD. Statistical analyses were carried out by Student's t-test. A p-value $<0.05$ was considered statistically significant.

\section{Results}

HDAC inhibitors and beta cell-specific transcription factors. Low concentrations of TSA, 0.01 and $0.1 \mu \mathrm{M}$, did not affect gene expression levels of Pdx1 or Mafa. However, $1 \mu \mathrm{M}$ TSA suppressed expression of Pdx1 and Mafa, and Txnip expression was enhanced by 0.1 and $1 \mu \mathrm{M}$ TSA (Figure 1). Thus, $1 \mu \mathrm{M}$ TSA was used in this study otherwise stated. Other HDAC inhibitors, $10 \mathrm{mM}$ VPA or $10 \mathrm{mM} \mathrm{NaB}$, also inhibited gene expression of Pdxl or Mafa but enhanced Txnip expression (Figure 2). MIN6 cells were cultured with or without $1 \mu \mathrm{M}$ TSA for $24 \mathrm{~h}$ then stained using DAPI to count the number of nuclei. The protein expression of Pdx1 and Mafa were assessed by immunocytochemistry (Figure 3). Pdx1 and Mafa were detected in the nuclei of control MIN6 cells but this was reduced by TSA treatment. Thus, TSA treatment inhibited Pdx1 and Mafa expression at transcription and translation levels. 


\section{Insulin secretion and insulin content of MIN6} cells. Insulin secretion was assessed by static incubation of MIN6 cells. Basal insulin secretion, assessed by incubation with 3 and $9 \mathrm{mM}$ glucose, was significantly increased by TSA. However, glucose-induced insulin secretion using 15 and $25 \mathrm{mM}$ glucose was significantly suppressed (Figure 4). TSA did not affect the insulin content of MIN6 cells (Figure 5). These results showed that TSA had a biphasic effect on insulin secretion. As insulin content was

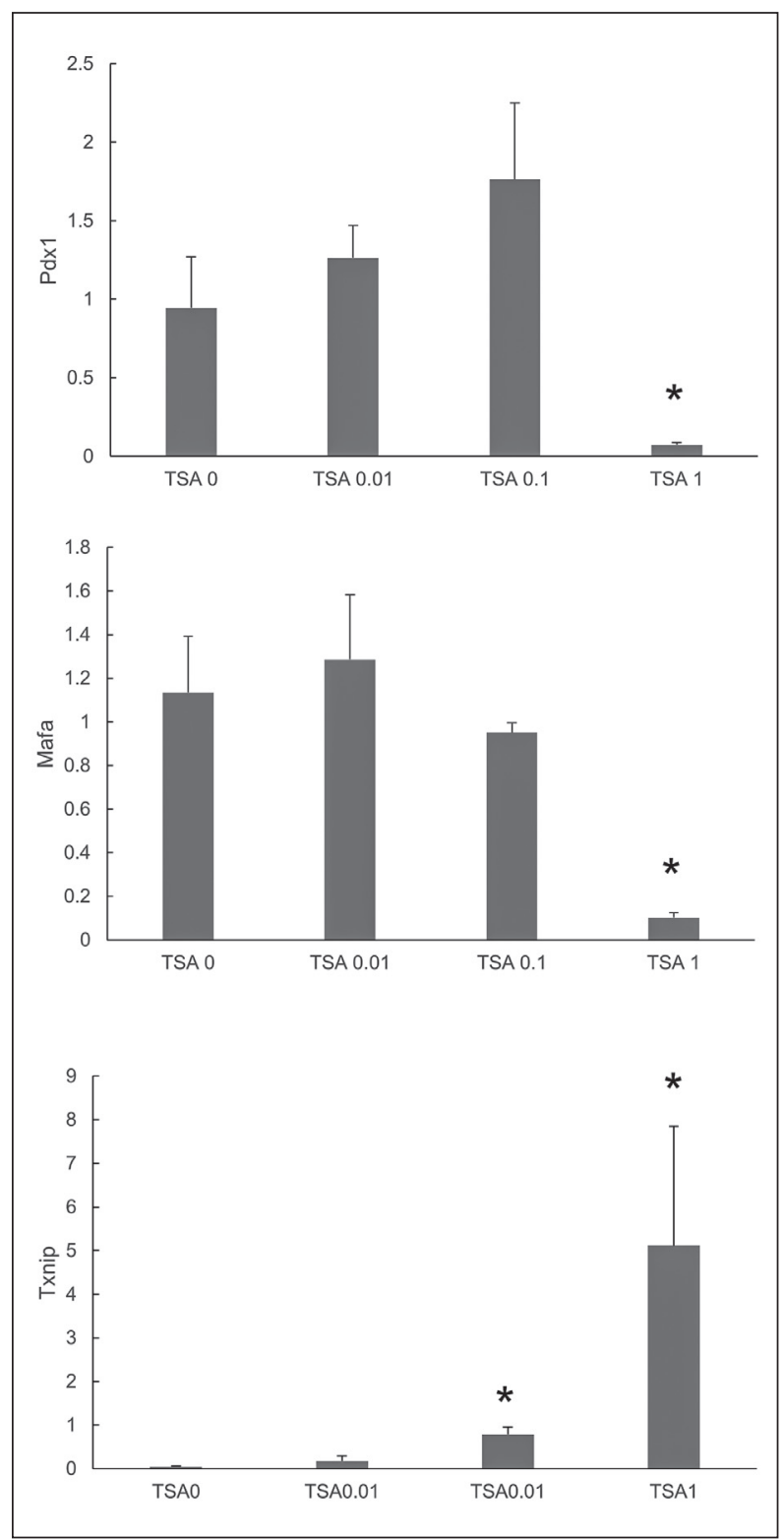

Figure 1. Quantitative RT-PCR analysis. Expression of Pdx1, Mafa, and Txnip genes in MIN6 cells cultured with 0, 0.01, 0.1 , and $1 \mu \mathrm{M}$ TSA for $24 \mathrm{~h}$. Values are means $\pm S D, n=4-5$, ${ }^{*} \mathrm{p}<0.05$. not affected by TSA, we concluded that TSA influenced the secretory machinery for insulin exocytosis but not production.

Hydrogen peroxide-induced ROS production. $\mathrm{H}_{2} \mathrm{O}_{2}$-induced ROS production was determined in response to TSA in MIN6 cells (Figure 6). ROS intensity in MIN6 cells was significantly increased by TSA. Therefore, TSA enhanced $\mathrm{H}_{2} \mathrm{O}_{2}$-induced ROS production suggesting that it increased the sensitivity to ROS-producing agents in pancreatic beta cells.

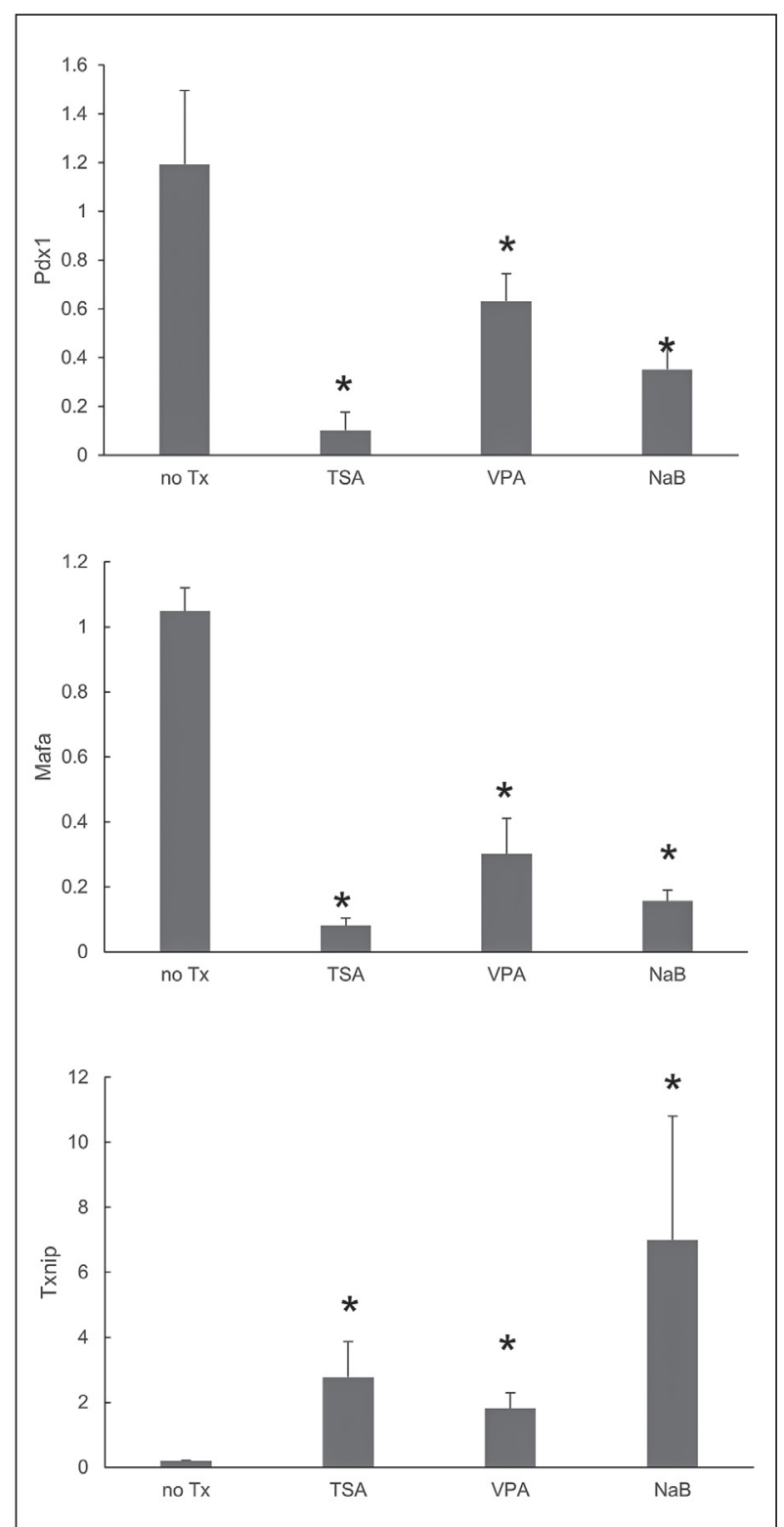

Figure 2. Quantitative RT-PCR analysis. Expression of Pdx1, Mafa, and Txnip genes in MIN6 cells cultured with $1 \mu \mathrm{M}$ TSA, $10 \mathrm{mM}$ VPA, or $10 \mathrm{mM} \mathrm{NaB}$ for $24 \mathrm{~h}$. Values are means $\pm \mathrm{SD}$, $\mathrm{n}=4-5,{ }^{*} \mathrm{p}<0.05$. 


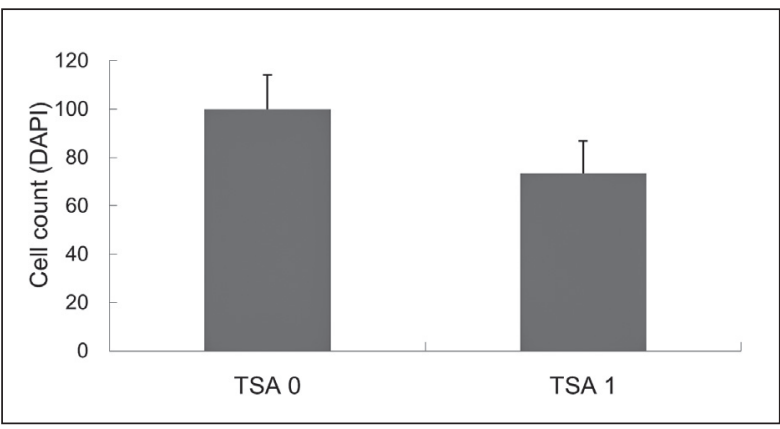

Figure 3. Immunocytochemical analysis of Pdx1 and Mafa proteins in the MIN6 cells. MIN6 cells were cultured with and without $1 \mu \mathrm{M}$ TSA for $24 \mathrm{~h}$ and then stained with anti-Pdx 1 or anti-Mafa antibodies.

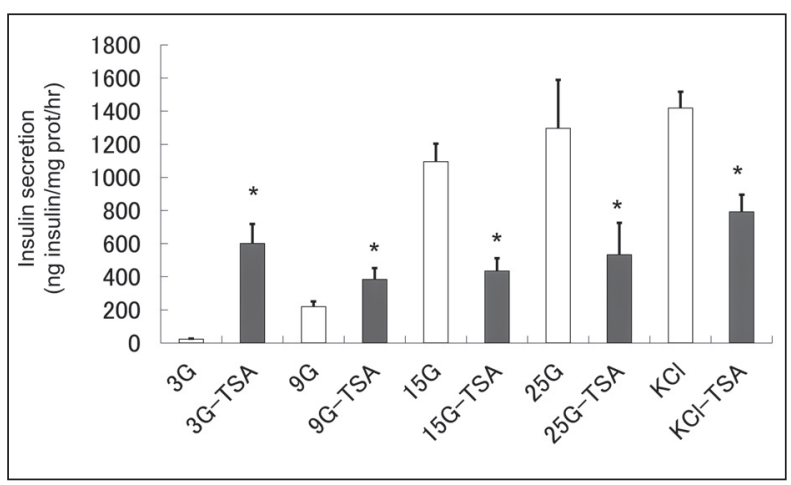

Figure 4. Effect of TSA on insulin secretion from MIN6 cells. MIN6 cells were cultured with and without $1 \mu \mathrm{M}$ TSA for $24 \mathrm{~h}$, followed by measurement of stimulated insulin secretion using $3(3 \mathrm{G}), 9(9 \mathrm{G}), 15(15 \mathrm{G})$, or $25 \mathrm{mM}$ (25G) glucose, or $30 \mathrm{mM} \mathrm{KCl}$. Values are means $\pm S D, n=5-6,{ }^{*} p<0.05$; insulin secretion from MIN6 cells treated with TSA vs. without TSA by Student's t-test.

\section{Discussion}

Our results showed that high doses of HDACis had a dual effect on insulin secretion in a pancreatic beta cell line, increasing basal insulin secretion but inhibiting glucose-induced insulin secretion. Gene expression of the transcription factors Pdx1 and Mafa was suppressed by HDACis, whereas Txnip gene expression was enhanced.

High doses of HDACis are known to be harmful to cells as induce cell cycle arrest and apoptosis (Zhang and Zhong 2014). Therefore, it is possible that suppression of several transcription factor genes, shown in our study, was a result of cell toxicity. However, as basal insulin secretion was enhanced by TSA, the effects of the HDACis were not solely due to a possible deterioration caused by a high dose.

We found that HDACis downregulated genes relevant to pancreatic function, Pdx1 and Mafa and up-

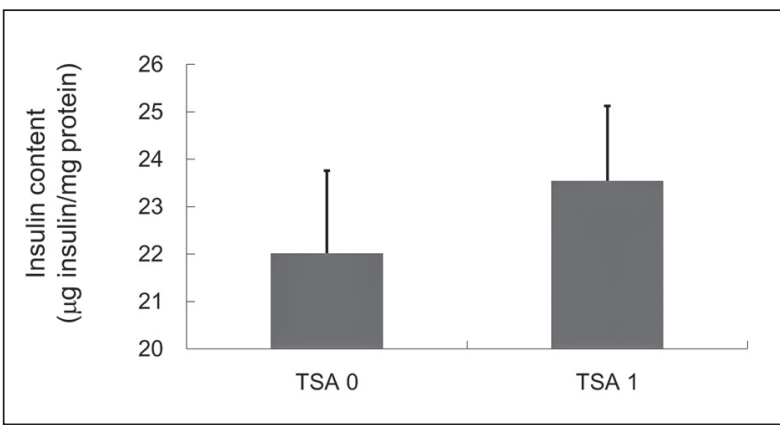

Figure 5. Insulin content of MIN6 cells. Insulin content was measured following treatment with TSA for $24 \mathrm{~h}$. Values are means $\pm \mathrm{SD}, \mathrm{n}=5-6$.

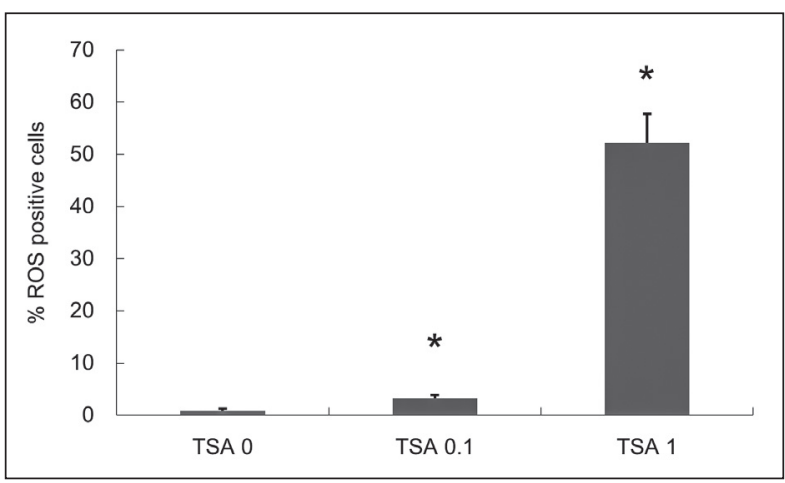

Figure 6. ROS production in MIN6 cells after TSA treatment. Hydrogen peroxide-induced ROS production was determined with and without TSA in MIN6 cells. Values are means \pm SD, $\mathrm{n}=11,{ }^{*} \mathrm{p}<0.05$ by Student's t-test.

regulated expression of Txnip. Xu et al. (2013) have reported that Txnip inhibited Mafa gene expression through induction of mir-204. They also reported that forced expression of Txnip did not influence the expression of Pdx1. Kubicek et al. (2012) have revealed that hydroxamic acid, a group of HDACis, inhibited gene expression of beta cell markers including Pdx1. These data showed that HDACi-induced suppression of Pdx1 may be caused by a mechanism other than Txnip induction.

Several reports have shown that Txnip/TBP2, a negative regulator of thioredoxin (Schulze et al. 2004), is increased by hyperglycemia and upregulated in the pancreas of diabetic animals (Minn et al. 2005). Txnip exerts its proapoptotic effect at least in part by inhibiting thioredoxin and inducing oxidative stress. It is also well known that Txnip is strongly upregulated by high glucose concentrations. Thus, it is postulated that hyperglycemia di- 
rectly decreases thioredoxin activity by increasing Txnip resulting in an increased apoptotic signal in pancreatic beta cells. We also showed that forced expression of the thioredoxin gene in pancreatic beta cells using insulin promoter prevented destruction of pancreatic beta cells in both type 1 (Hotta et al. 1998) and type 2 diabetes models (Yamamoto et al. 2008).

Txnip is also reported to be upregulated by HDACi by the CCAAT element and NF-YA of the Txnip promoter region (Butler et al. 2002). These results suggest that HDACis could directly induce the expression of Txnip. Indeed, TSA has been reported to induce Txnip gene expression in the INS-1 rat pancreatic beta cell line (Cha-Molstad et al. 2009). A recent report has also shown that another $\mathrm{HDACi}$, CI994, increased Txnip gene expression through activation of histone acetyl transferase p300 in INS-1 cells (Bompada et al. 2016). Another HDACi, SAHA, also increased Txnip levels, leading to increased ROS (Ungerstedt et al. 2012). It has been also reported that overexpression of Txnip enhanced $\mathrm{H}_{2} \mathrm{O}_{2}$-induced oxidative stress (Junn et al. 2000) leading to dereg- ulated insulin secretion from pancreatic beta cells. Indeed, our results also showed that $\mathrm{H}_{2} \mathrm{O}_{2}$-induced ROS production was enhanced by TSA treatment.

Our results showed that basal insulin secretion was enhanced by TSA. Certain levels of oxidative stress induced by glucose challenge have been shown to be a requisite for insulin secretion ( $\mathrm{Pi}$ et al. 2007; Saadeh et al. 2012; Fu et al. 2013; Llanos et al. 2015). We showed that ROS production was enhanced by TSA. Therefore, the increased oxidative level of pancreatic beta cells induced by TSA may result in enhanced basal insulin secretion.

Our results showed that HDACis caused failure to suppress insulin secretion at low glucose concentrations and enhance insulin secretion at high glucose concentrations. In other words, when these HDACis are used clinically, high doses of HDACis may cause hypoglycemia in the fasting state and hyperglycemia in the fed state.

In conclusion, our results reveal that HDACis could modulate the insulin secretory capacity through oxidative stress. This modulation should be considered in the clinical use of HDACis.

\section{References}

Bompada P, Atac D, Luan C, Andersson R, Omella JD, Laakso EO, Wright J, Groop L, De Marinis Y. Histone acetylation of glucose-induced thioredoxin-interacting protein gene expression in pancreatic islets. Int J Biochem Cell Biol 81, 82-91, 2016.

Butler LM, Zhou X, Xu WS, Scher HI, Rifkind RA, Marks PA, Richon VM. The histone deacetylase inhibitor SAHA arrests cancer cell growth, up-regulates thioredoxin-binding protein-2, and down-regulates thioredoxin. Proc Natl Acad Sci U S A 99, 11700-11705, 2002.

Cha-Molstad H, Saxena G, Chen J, Shalev A. Glucose-stimulated expression of Txnip is mediated by carbohydrate response element-binding protein, p300, and histone $\mathrm{H} 4$ acetylation in pancreatic beta cells. J Biol Chem 284, 16898-16905, 2009.

Christensen DP, Dahllof M, Lundh M, Rasmussen DN, Nielsen MD, Billestrup N, Grunnet LG, Mandrup-Poulsen T. Histone deacetylase (HDAC) inhibition as a novel treatment for diabetes mellitus. Mol Med 17, 378-390, 2011.

Fu J, Zhang Q, Woods CG, Zheng H, Yang B, Qu W, Andersen ME, Pi J. Divergent effects of sulforaphane on basal and glucose-stimulated insulin secretion in b-cells: role of reactive oxygen species and induction of endogenous antioxidants. Pharm Res 30, 2248-2259, 2013.

Halsall J, Gupta T, O’Neill LP, Turner BM, Nightingale KP. Genes are often sheltered from the global histone hyperacetylation induced by HDAC inhibitors. PLoS One 7, e33453, 2012.

Hotta M, Tashiro F, Ikegami H, Niwa H, Ogihara T, Yodoi J, Miyazaki J. Pancreatic beta cell-specific expression of thioredoxin, an antioxidative and antiapoptotic protein, prevents autoimmune and streptozotocin-induced diabetes. J. Exp Med 188, 1445-1451, 1998.

Junn E, Han SH, Im JY, Yang Y, Cho EW, Um HD, Kim DK, Lee KW, Han PL, Rhee SG, Choi I. Vitamin D3 up-regulated protein 1 mediates oxidative stress via suppressing the thioredoxin function. J Immunol 164, 6287-95, 2000.

Khan S, Jena GB. Protective role of sodium butyrate, a HDAC inhibitor on beta-cell proliferation, function and glucose homeostasis through modulation of p38/ERK MAPK and apoptotic pathways: study in juvenile diabetic rat. Chem Biol Interact 213, 1-12, 2014.

Khan S, Jena G. The role of butyrate, a histone deacetylase inhibitor in diabetes mellitus: experimental evidence for therapeutic intervention. Epigenomics 7, 669-80, 2015. 
Kubicek S, Gilbert JC, Fomina-Yadlin D, Gitlin AD, Yuan Y, Wagner FF, Holson EB, Luo T, Lewis TA, Taylo B, Gupta S, Shamji AF, Wagner BK, Clemons PA, Schreiber SL. Chromatin-targeting small molecules cause class-specific transcriptional changes in pancreatic endocrine cells. Proc Natl Acad Sci U S A 109, 5364-5369, 2012.

Larsen L, Tonnesen M, Ronn SG, Storling J, Jorgensen S, Mascagni P, Dinarello CA, Billestrup N, Mandrup-Poulsen T. Inhibition of histone deacetylases prevents cytokine-induced toxicity in beta cells. Diabetologia 50, 779789, 2007.

Llanos P, Contreras-Ferrat A, Barrientos G, Valencia M, Mears D, Hidalgo C. Glucose-Dependent Insulin Secretion in Pancreatic $\beta$-Cell Islets from Male Rats Requires Ca2+ Release via ROS-Stimulated Ryanodine Receptors. PLoS One 10, e0129238, 2015.

Lundh M, Christensen DP, Damgaard Nielsen M, Richardson SJ, Dahllof MS, Skovgaard T, Berthelsen J, Dinarello CA, Stevenazzi A, Mascagni P, Grunnet G, Morgan NG, Mandrup-Poulsen T. Histone deacetylases 1 and 3 but not 2 mediate cytokine-induced beta cell apoptosis in INS-1 cells and dispersed primary islets from rats and are differentially regulated in the islets of type 1 diabetic children. Diabetologia 55, 2421-2431, 2012.

Lundh M, Galbo T, Poulsen SS, Mandrup-Poulsen T. Histone deacetylase 3 inhibition improves glycaemia and insulin secretion in obese diabetic rats. Diabetes, Obes Metab 17, 703-707, 2015.

Manal M, Chandrasekar MJN, Gomathi Priya J, Nanjan MJ. Inhibitors of histone deacetylase as antitumor agents: A critical review. Bioorg Chem 67, 18-42, 2016.

Marks PA. Histone deacetylase inhibitors: a chemical genetics approach to understanding cellular functions. Biochim Biophys Acta 1799, 717-725, 2010.

Minn AH, Hafele C, Shalev A. Thioredoxin-interacting protein is stimulated by glucose through a carbohydrate response element and induces beta-cell apoptosis. Endocrinology 146, 2397-2405, 2005

Miyazaki J, Araki K, Yamato E, Ikegami H, Asano T, Shibasaki Y, Oka Y, Yamamura K. Establishment of a pancreatic beta cell line that retains glucose-inducible insulin secretion: special reference to expression of glucose transporter isoforms. Endocrinology 127, 126-32, 1990.

Newbold A, Falkenberg KJ, Prince HM, Johnstone RW. How do tumor cells respond to HDAC inhibition? FEBS J 283, 4032-4046, 2016.

Pi J, Bai Y, Zhang Q, Wong V, Floering LM, Daniel K, Reece, JM, Deeney JT, Andersen ME, Corkey BE, Collins S. Reactive oxygen species as a signal in glucose-stimulated insulin secretion. Diabetes 56, 1783-1791, 2007.

Plaisance V, Rolland L, Gmyr V, Annicotte JS, Kerr-Conte J, Pattou F, Abderrahmani A. The class I histone deacetylase inhibitor MS-275 prevents pancreatic beta cell death induced by palmitate. J Diabetes Res 2014, 195739, 2014.

Saadeh M, Ferrante TC, Kane A, Shirihai O, Corkey BE, Deeney JT. Reactive oxygen species stimulate insulin secretion in rat pancreatic islets: studies using mono-oleoyl-glycerol. PLoS One 7, e30200, 2012.

Schulze PC, Yoshioka J, Takahashi T, He Z, King GL, Lee RT. Hyperglycemia promotes oxidative stress through inhibition of thioredoxin function by thioredoxin-interacting protein. J Biol Chem 279, 30369-30374, 2004.

Sharma S, Taliyan R. Histone deacetylase inhibitors: Future therapeutics for insulin resistance and type 2 diabetes. Pharmacol Res 113, 320-326, 2016.

Susick L, Veluthakal R, Suresh MV, Hadden T, Kowluru A. Regulatory roles for histone deacetylation in IL-1betainduced nitric oxide release in pancreatic beta-cells. J Cell Mol Med 12, 1571-1583, 2008.

Tiernan AR, Champion JA, Sambanis A. Trichostatin A affects the secretion pathways of beta and intestinal endocrine cells. Exp Cell Res 330, 212-21, 2015.

Ungerstedt J, Du Y, Zhang H, Nair D, Holmgren A. In vivo redox state of Human thioredoxin and redox shift by the histone deacetylase inhibitor suberoylanilide hydroxamic acid (SAHA). Free Radic Biol Med 53, 2002-2007, 2012.

Xu G, Chen J, Jing G, Shalev A. Thioredoxin-interacting protein regulates insulin transcription through microRNA-204. Nat Med 19, 1141-1146, 2013.

Yamamoto M, Yamato E, Toyoda S, Tashiro F, Ikegami H, Yodoi J, Miyazaki J. Transgenic expression of antioxidant protein thioredoxin in pancreatic beta cells prevents progression of type 2 diabetes mellitus. Antioxid Redox Signal 10, 43-49, 2008.

Yamato E, Tashiro F, Miyazaki J. Microarray analysis of novel candidate genes responsible for glucose-stimulated insulin secretion in mouse pancreatic $\beta$ cell line MIN6. PLoS One 8, e61211, 2013.

Zhang J, Zhong Q. Histone deacetylase inhibitors and cell death. Cell Mol Life Sci 71, 3885-901, 2014. 